\title{
Case not closed
}

\author{
The FBI says it has evidence showing that Bruce lvins was behind the 2001 anthrax attacks - but with his \\ death, this will not be tested in court. A full enquiry into the case is needed if justice is to be done.
}

W as Bruce Ivins a scientist-gone-wrong who singlehandedly orchestrated the 2001 anthrax attacks in the United States? Or was the 62-year-old anthrax-vaccine researcher at Fort Detrick, Maryland, an emotionally unstable innocent whose profile made him a convenient fall guy for the FBI?

The jury is still out on those questions - or rather, it would be if one had ever had a chance to hear the evidence. Ivins's apparent suicide last month means there will not be a trial, which makes it all the more important that the government release the evidence it planned to use to accuse him. In full. Now.

On 6 August, the FBI's parent agency, the US Department of Justice, released what it described as hundreds of pages of evidence against Ivins, and declared it would close the case because it was satisfied it had its man. But Ivins's attorney, Paul Kemp, has described these documents as "heaps of innuendo and a staggering lack of real evidence". He has a point.

For example, many of the documents are just search warrants - a reminder that, despite extensive searches of Ivins's house and cars, the FBI failed to come up with any physical evidence directly implicating him in the attacks. Similarly, the bureau has no evidence to place Ivins at the postboxes in Princeton, New Jersey, from which the anthraxladen letters were sent.

The core of the case against Ivins, as released so far, is contained in just a couple of dozen pages of affidavits - only four paragraphs of which discuss what the FBI says is the smoking gun: the genetic analysis of the anthrax powder from the letters. The FBI says it found four distinctive genetic mutations in the anthrax used in the attacks. It tested for these mutations in isolates of the Ames anthrax strain from 16 domestic, government and university laboratories, alongside ones from labs in Canada, Sweden and the United Kingdom.

In all, more than 1,000 samples were collected, only 8 of which had the 4 mutations, according to the affidavit. Each of these isolates, it says, was directly related to a strain batch named RMR-1029, which was created in 1997 and held in a flask at the US Army research facility in Fort Detrick. The affidavits describe Ivins as the "sole custodian" of that batch. Many other researchers had access to it, but the FBI claims to have eliminated them as suspects.

The genetic analysis itself seems quite solid. The FBI has collaborated with some of the best outside scientists on anthrax, and on 18 August convened many of them to answer journalists' questions about the science. The researchers on the panel explained that none of the analysis techniques used in this case is new; just the application to "Only full disclosure can lift suspicions that the FBI has again targeted an innocent man." anthrax forensics. Several peer-reviewed papers on the forensic work have already been published, and another dozen or so are anticipated (see page 928 ).

Although this openness about the techniques is commendable, neither the conclusions drawn from the scientific analysis, nor such crucial legal elements as the veracity of the provenance and handling of samples, have been tested in court. So far only one side of the story has been heard: that of the prosecution.

Certainly Ivins's behaviour in the crucial autumn months of 2001 raises questions about his emotional stability, but mental illness does not necessarily a murderer make.

The FBI should explain why it thinks the scientific evidence implicates Ivins himself, and not just the flask. As Kemp aptly puts it: "In this country, we prosecute people, not beakers." The absence of such a full disclosure can only feed suspicions that the FBI has again targeted an innocent man in this case - as it did with former Fort Detrick researcher Steven Hatfill.

This case is too important to be brushed under the carpet. The anthrax attacks killed five people, infected several others, paralysed the United States with fear and shaped the nation's bioterrorism policy. Science and law share a conviction that conclusions require evidence, and that the evidence be debated openly. The FBI says it regrets that Ivins's untimely death has denied it the chance to have its day in court. So presumably the bureau would welcome a full congressional or independent enquiry into this case, as has been called for by Senator Chuck Grassley (Republican, Iowa) and several other lawmakers. It is essential that such an enquiry takes place.

\section{Scandalous behaviour}

\section{Austria's most serious report of scientific misconduct in recent memory must be handled properly.}

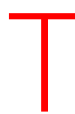
he academic community in Austria often seems to be a closed, elite set, especially in the sphere of medicine. The power and influence wielded by a professor are hard to understand from the outside, and the rigid hierarchy of the academic system has been hard to dismantle from the inside, despite reformers' best efforts.

The upper echelons of that community also seem to know how to close ranks. Witness an example now threatening to emerge from the Medical University of Innsbruck, where there are worrying signs that investigations into a scandal of unprecedented dimensions in this small country may be thwarted.

According to a report from the Austrian Agency for Health and Food Safety, a urologist at the university, Hannes Strasser, has conducted a high-profile clinical trial so inappropriately that it must be considered entirely invalid (see page 922). Moreover, that trial 